DOI 10.37882/2223-2982.2021.12.31

\title{
ПРОГРАММЫ ПОЛИТИЧЕСКИХ ПАРТИЙ И ДВИЖЕНИЙ РОССИИ В 2003-2004 Г.: ДИСКУССИИ О ФИНАНСОВЫХ РЕСУРСАХ МОДЕРНИЗАЦИИ
}

\section{RUSSIAN POLITICAL PARTIES AND MOVEMENTS PROGRAMS IN 2003- 2004: DISCUSSIONS ON THE FINANCIAL RESOURCES FOR MODERNIZATION}

\section{A. Sukiasyan}

Summary: The paper deals with the concepts of state investment policy that were included in the program documents of political parties and movements of the Russian Federation during the parliamentary elections of 2003 and the presidential campaign in 2004. By investment policy, the author understands a set of doctrines and managerial decisions that determine the sources of formation, goals and methods of using financial resources aimed at the development of the country. The research task is to form scientific ideas about the content and results of socio-political discussions on the problems of state investment policy in Russia in the early 2000s. The paper was carried out on the basis of general scientific approaches and applied methods of historical and socio-humanitarian research: content analysis, comparative method, system analysis, etc. The novelty of the research is determined by the first comprehensive study of election programs and other public documents of the leading political parties and social movements in Russia in the early 2000s from a thematic perspective of state investment policy. The author notes that the economic policy of the Russian leadership received the support of the majority of voters in 2003-2004. And this policy including the combination of state financing of the strategic directions of the country's development with the stimulation of the activity of private business has shown its effectiveness in subsequent years. The results of the work can be used in the development of programs for the state investment policy of Russia, as well as in scientific and educational activities in universities of the humanitarian and financial profile.

Keywords: history of social and political thought, market reforms, modernization of Russia, parliamentary elections in Russia, presidential elections in Russia, political parties, State Duma of Russia, investment policy, budget policy, private investment.

\author{
Сукиасян Асатур Альбертович \\ К.э.н., доцент, Башкирский \\ государственный университет \\ saa@s-lab.info
}

Аннотация: Статья посвящена концепциям государственной инвестиционной политики, вошедшим в программные документы политических партий и движений Российской Федерации в период парламентских выборов 2003 и президентской кампании 2004 г. Под инвестиционной политикой автор понимает комплекс доктрин и управленческих решений, определяющих источники формирования, цели и методы освоения финансовых ресурсов, направляемых на развитие страны. Целью работы является формирование научных представлений о содержании и результатах общественно-политических дискуссий по проблемам государственной инвестиционной политики в России начала 2000-х гг.

Работа выполнена на основе общенаучных подходов и прикладных методов исторических и социально-гуманитарных исследований: контент-анализа, компаративного метода, системного анализа и др.

Новизна исследования определяется впервые проведенным комплексным изучением предвыборных программ и публицистических документов ведущих политических партий и общественных движений России начала 2000-х гг. в тематическом ракурсе государственной инвестиционной политики. Автор отмечает, что получившая поддержку большинства избирателей в 2003-2004 гг. экономическая политика руководства России, включая сочетание государственного финансирования стратегических направлений развития страны со стимулированием активности частного бизнеса, показала свою эффективность в последующие годы. Результаты работы могут быть использованы при разработке программ государственной инвестиционной политики России, а также в научной и образовательной деятельности в вузах гуманитарного и финансового профиля.

Ключевые слова: история общественно-политической мысли, рыночные реформы, модернизация России, парламентские выборы в России, президентские выборы в России, политические партии, Государственная Дума России, инвестиционная политика, бюджетная политика, частные инвестиции.

\section{Введение}

A ктуальность исследования обусловлена значимостью общественного дискурса в процессе формирования стратегии развития России в XXI веке и реализации задач социально-экономической модернизации страны в условиях сложной геополитической обстановки современности. Существенный научно-те- оретический интерес представляет ретроспективное изучение подходов ведущих российских политических партий, движений, общественных организаций к наиболее значимым аспектам государственной политики в 2000-е гг., когда происходила разработка и апробация государственно-политической и экономической модели, соответствующей новому этапу модернизационного транзита России. В частности, отдельного рассмотрения 
заслуживает в данном контексте период подготовки и проведения в Российской Федерации парламентских и президентских выборов в 2003-2004 гг., ставших одной из важных вех в становлении современной российской государственности и развитии общественно-политической мысли.

В российской истории постсоветского периода важное место занимает государственная инвестиционная политика, которая определяет приоритеты бюджетных капиталовложений, правовые нормы и механизмы взаимодействия власти с частными инвесторами, формируя финансовые ресурсы для развития экономики и общества. Инвестиционная политика выступает одним из важнейших инструментов реализации модернизационного курса страны в XXI веке. Президент России В.В. Путин, выступая на Совещании о мерах по стимулированию инвестиционной активности 11 марта 2021 г., подчеркнул, что стимулирование инвестиций - это «важнейший вопрос для повышения темпов и качества экономического роста в нашей стране, для увеличения занятости и доходов граждан» [1].

Концепции и задачи инвестиционной политики отражены в программных документах большинства российских политических партий и движений, являясь важным индикатором их идеологического облика и практических позиций в макроэкономической области, а также по таким вопросам как взаимодействие власти и бизнеса, налоговая и бюджетная политика, развитие научнотехнологической, образовательной, социальной сферы, модернизация регионов и др. [2].

Существенную роль тема государственных и частных капиталовложений в развитие страны играла в ходе предвыборных дискуссий 2003-2004 гг. и, соответственно, в дальнейшей реализации избранного курса российским руководством. Электоральным событиям 20032004 гг. посвящен ряд исследований политологического профиля, основное внимание в которых уделяется персоналиям российских политиков и особенностям их избирательных кампаний. Различные аспекты формирования ведущими политическими силами Российской Федерации стратегии социально-экономического развития страны в 2000-е гг. рассматриваются в публикациях В.Ф. Ершова, И.В. Курлевского, М.Б. Чистого и ряда других авторов [3; 4; 5]. Однако позиции российских политических партий и движений в сфере инвестиционной политики не нашли до настоящего момента отражения В научных исследованиях. В настоящей статье представлены результаты проведенного автором сравнительного анализа содержания предвыборных программ, выступлений, интервью и других материалов в целях выявления роли и места инвестиционной проблематики в процессе общественно-политических дискуссий

\section{3-2004 гг.}

В работе изучаются, прежде всего, документы и заявления тех политических движений, представители которых вошли в состав Государственной Думы РФ IV созыва («Единая Россия», КПРФ, ЛДПР, блок «Родина») и в последующий период участвовали в формировании концепций финансово-экономической, в том числе инвестиционной политики страны и системы административного регулирования инвестиционной деятельности, а также материалы деятельности общественно-политических сил, наиболее активно участвовавших в электоральных процессах в рассматриваемый период (СПС, «Яблоко» и др.)

\section{Обсужмение}

На рубеже 1990-х - 2000-х гг. начинается трансформация концепции государственной инвестиционной политики Российской Федерации На начальном этапе рыночных реформ участие государства в финансировании экономики было минимизировано, в качестве стратегического приоритета в данной сфере выступало привлечение в страну иностранных инвестиций, притом, что нормативно-правовая база инвестиционной деятельности в России находилась в процессе формирования. Принятие в 1999 г. пакета федеральных законов, регулирующих инвестиционную сферу, курс на укрепление государственности и социально-экономическую модернизацию России, создали основу для становления принципиально новой для России модели государственной инвестиционной политики. Еще в марте 2000 г. в ходе заседания Консультационного совета по иностранным инвестициям Президент России В.В. Путин высказался в пользу мобилизации внутренних финансовых резервов страны как основы для продолжения курса реформ [6]. В то же время мероприятия по созданию в стране благоприятного инвестиционного климата и привлечению в российскую экономику иностранных инвестиционных капиталов оставались одним из центральных направлений внутренней и внешней экономической политики Российской Федерации [7]. В этом ключе концепция инвестиционной политики выстраивалась в документах партии «Единая Россия» и президентской программе В.В. Путина в 2003-2004 гг.

Перед выборами 2003 г. в Государственную Думу IV созыва ЦИК РФ зарегистрировал федеральные списки 23 партий и избирательных блоков, программы большинства которых в той или иной степени затрагивали тему инвестиций - источников их формирования, целевой направленности, объемов, баланса между государственными и частными капиталовложениями в российскую экономику и социально-культурную сферу. Практически все участники предвыборной кампании декларировали 
свои намерения наращивать капиталовложения в технологическую и структурную модернизацию стратегически значимых отраслей промышленности, науку, образование, поддержку социально незащищенных слоев населения. Принципиальные различия существовали в понимании источников формирования инвестиционных финансовых ресурсов. Так, правые (в российской политической модели - либеральные) движения делали ставку на максимальное развитие отечественного частного сектора и расширение сотрудничества с иностранными инвесторами через использование налоговых и организационных льгот; КПРФ, Аграрная партия России и другие левые движения заявляли о необходимости возвращения к советской модели государственного распределения финансовых ресурсов. «Единая Россия» и близкие к ней партии и организации являлись сторонниками комплексного механизма формирования и распределения финансовых ресурсов развития страны, что предполагало создание экономических условий для наращивания объемов государственного бюджета и, соответственно, целевых государственных инвестиций; в то же время, стимулирование инвестиционной активности отечественного и иностранного частного капитала.

В программе партии «Единая Россия», утвержденной на III Съезде ЕP 20 сентября 2003 г., предлагался комплекс мер по модернизации российской экономики, финансов, налоговой и бюджетной политики, направленный на создание единого экономического пространства России. В том числе выделялись задачи в сфере обеспечения равноправных и прозрачных условий промышленной и коммерческой деятельности недропользователей с обеспечением финансовых интересов государства как собственника природных ресурсов, подчеркивалась обязанность государства регулировать и поддерживать развитие стратегически значимых отрасли - транспорта, энергетики, сельского хозяйства, ЖКХ и ВПК[8]. На первый план «Единая Россия выдвигала также применение, прежде всего, экономических методов регулирования, обеспечение прозрачности налоговой политики и сокращение надзорной деятельности за частным предпринимательством, не участвующим в стратегических отраслях экономики, а также выступала за смешанную (государственно-частную) систему финансирования развития образования и медицины Одним из ключевых социальных проектов «Единой России» выступало создание системы обязательного медицинского страхования (ОМС) в целях обеспечения высокого качества и доступности медицины [8].

Учитывая объективный характер процессов глобализации и международной экономической конкуренции «Единая Россия» высказывалась в пользу дальнейшего внедрения в стране мировых стандартов ведения бизнеса, включая вступление страны в ВТО, и расширения сотрудничества с иностранными инвесторами.

В декабре 2003 г. в прямом эфире российского Центрального телевидения была представлена президентская программа В.В. Путина, в которой провозглашалась приверженность базовым принципам рыночных реформ при обеспечении эффективного государственного регулирования экономических процессов: «Когда страна начинала приватизацию, мы исходили из того, что частный собственник будет более эффективным, чем государство. Так оно и есть. Но здесь есть элемент, который нельзя забывать: в развитых экономиках существует отлаженная система администрирования, через которую государство решает социальные задачи» [9, с.1].

Следует отметить, что далеко не все программы политических партий и избирательных блоков включали конкретные разделы или тезисы, отражавшие их позиции в отношении государственной инвестиционной политики. Так, в программе ЛДПР тема инвестиционной политики практически игнорировалась, лишь кратко говорилось о задачах увеличения финансирования государством российской фундаментальной науки [8].

КПРФ и их сторонники отстаивали идею резкого многократного увеличения социальных выплат и зарплат, не считаясь с реальными возможностями бюджета и частного бизнеса. Примечательно, что эта идея, которую КПРФ предлагала вынести на всенародный референдум, не встретила ожидаемой коммунистами массовой поддержки. Показателен, в частности, вопрос, заданный лидеру КПРФ в рамках проекта «Спросите Зюганова» о том, где компартия предполагает получить дополнительные финансовые ресурсы и что при этом произойдет с экономикой страны: «В соответствии с экономической теорией и здравым смыслом подобный шаг приведет к плачевным последствиям: прибыль компаний резко упадет, а вместе с ней и инвестиции. Компаниям нечего будет вкладывать в реальное производство, так как средства уйдут на зарплату и ЕСН. Таким образом, подрывается основа будущего экономического роста. Подобные популистские заявления только усиливают резко негативное отношение к компартии со стороны экономически образованного населения», - отмечал автор вопроса [10]. Г.А. Зюганов уклонился от ответа, сказав только, что стране «нужна новая стратегическая политика» [10].

Лидер блока «Родина» С.Ю. Глазьев указывал в своих интервью, научных и публицистических работах начала 2000-х гг. на необходимость увеличения в два-три раза бюджетных капиталовложений в основные производственные фонды, а также в приоритетное развитие стратегически значимых отраслей, обладающих потенциалом быстрого роста и высокой конкурентоспособности на мировых рынках: наукоемкого машиностроения, 
биотехнологий, телекоммуникаций, авиакосмического комплекса, информационных услуг. Предвыборные программы блока «Родины» и лично С.Ю. Глазьева, выдвигавшегося в 2004 г. на президентский пост, включали привлечение в российскую экономику «длинных денег» с использованием таких механизмов как банки развития, бюджет развития, целевые федеральные программы, государственные гарантии; дополнительные бюджетные ресурсы политик предполагал получить через сокращение выплат по внешнему долгу [11] и создание механизма по возврату в казну сверхприбылей частных компаний [12].

Программа кандидата в президенты С.М. Миронова (на тот момент лидера «Российской партии жизни») также включала лозунг более сбалансированного распределения доходов от сырьевого экспорта, в том числе предлагалось замена налога на добычу полезных ископаемых акцизом, введение экспортной пошлины, привязанной к мировым ценам и др. Подход С.М. Миронова к финансово-экономической политике был близок к программе «Единой России» и В.В. Путина - создание эффективных рыночных отношений при сохранении исторически обусловленной высокой роли государства в экономике, приоритетным бюджетным инвестированием в инновационную промышленность, науку, поддержку сельского хозяйства и малого предпринимательства [13].

Активно продвигал свою экономическую повестку Союз правых сил (СПС) во главе Е.Т. Гайдаром. При этом для «Единой России», «Яблока» и КПРФ при всей разнице в идеологических и практических подходах к российской экономике на первом плане стояла цель преодоления социально-экономических проблем и дальнейшее инновационное развитие страны [8]. Для Е. Гайдара, А. Чубайса и других лидеров СПС главным было продолжение курса либеральных реформ даже ценой дальнейшего ухудшения текущей ситуации в экономике: «Сначала реформы, которые создадут хороший инвестиционный климат в стране; только потом может возникнуть ощутимый экономический подъем» [14]. Среди реальных мер в сфере модернизации страны программа СПС включала создание условий для увеличения частных инвестиций в сектор ЖКХ, прежде всего, в тепло- и водоснабжение населения [8].

Партией «Яблоко» во главе с Г.А. Явлинским декларировался рост государственных капиталовложений в образование, науку и социальную сферу, а также в возрождение и развитие малых городов через закрепление значительной доли налогов за местными бюджетами [8].

Из других партий и избирательных блоков, участвовавших в выборах в Государственную Думу IV созыва, но не прошедших 5 \% барьер, в контексте исследуемой проблемы следует упомянуть партию «Развитие предпринимательства» (председатель И.Д. Грачев), позднее преобразованную в одноименное общероссийское общественное движение [15]. Программа данной организации включала самостоятельный раздел «Инвестиционная политика», в котором предлагалось сосредоточить максимум ресурсов отечественного капитала и одновременно минимизировать иностранное участие в трех отраслях, способных стать локомотивами российской модернизации: аэрокосмическом секторе, энергетике, включая ТЭК и в энергетическом машиностроении. Авторы программы разъясняли значимость создания прибавочной стоимости в локомотивных отраслях исключительно инвесторами-резидентами с максимальной поддержкой их на внешних рынках. Одновременно партия «Развитие предпринимательства», апеллируя к опыту крупных западных диверсифицированных фирм, призывала отечественный бизнес осуществлять прямые инвестиции или вкладывать «оборотно-инвестиционным маневром» в производство и реализацию качественного товара на внутреннем рынке, опираясь на технологию управления добавочной стоимостью [8].

Результаты парламентских выборов 2003 г. и президентской кампании 2004 г. показали высокий уровень консолидации российского общества: большинство избирателей поддержало курс социально-экономической модернизации на основе сбалансированного подхода к участию государства и частного капитала в развитии страны, коррелирующего с общемировыми тенденциями в промышленно-технологической и инвестиционной политике [16, с.177]. Тем самым была обеспечена последовательная реализация начатой ранее руководством страны программы в области укрепления государственных институтов, участвующих в экономическом регулировании и взаимодействии с частным бизнесом [17].

Стабильный рост российской экономики, обеспечивший устойчивый бюджетный профицит в 2000-2007 гг. [18], способствовал расширению государственных капиталовложений в реализацию целевых федеральных и региональных программ. Одновременно осуществлялось создание институтов развития и внедрение в практику механизмов инвестиционной политики, сочетающих целевые бюджетные и частные капиталовложения и получивших поддержку российского делового сообщества $[19$, с. 69].

\section{Выводы}

Таким образом, анализ программ и проектов политических партий и движений 2003-2004 гг. свидетельствует о множественности подходов к теме обеспечения финансовыми ресурсами задач развития России в XXI веке. Продвижение тех или иных моделей государствен- 
ной инвестиционной политики в документах различных общественно-политических течений, определявшихся их методологическими различиями, стала частью предвыборной борьбы, выявляя тем самым стратегическую значимость инвестиционной сферы в системе финансово-экономического регулирования.
Итоги парламентских и президентских выборов 2003-2004 гг. обусловили утверждение сбалансированного подхода к формированию и использованию финансовых ресурсов модернизации страны и созданию платформы для современной модели государственной инвестиционной политики Российской Федерации.

\section{ЛИТЕРАТУРА}

1. Совещание о мерах по стимулированию инвестиционной активности 11 марта 2021 г. [Электронный ресурс] // Президент России. Официальный сайт. URL: http://www.kremlin.ru/events/president/news/65141 (Дата обращения: 10.10.2021)

2. Политические и экономические элиты российских регионов. / Отв. ред. О.В. Гаман-Голутвина. М.: Институт ситуационного анализа и новых технологий, 2004. 689 c.

3. Ершов В.Ф. Партия «Единая Россия» и концепция нового политического пространства: выборы, традиции, инновации // Педагогические исследования. Идеи и реальность: Сб. научных статей. Волгоград, 2010. С.106-114.

4. Курлевский И.В. Проекты модернизации национальной и региональной политики Российской Федерации в программных документах парламентских партий 1999 - 2003 годов // Инженерные технологии и системы. 2012. Вып.3-4. С.63-68.

5. Чистый М.Б. Социально-экономическая проблематика в программных документах влиятельных политических партий России. // Инновации и инвестиции. 2015. № 11. С. 153- 156.

6. Выступление Президента России В.В. Путина на заседании Консультационного совета по иностранным инвестициям Москва, Кремль 13 марта 2000 г. [Электронный ресурс] // Президент России. Официальный сайт. URL: http://www.kremlin.ru/events/president/transcripts/21203

7. Сукиасян А.А. Инвестиционные форумы в контексте развития международных экономических связей России в начале XXI в. // Экономика и социум: Электронный журнал. 2017. № 3.

8. Выборы депутатов Государственной Думы Федерального собрания РФ четвертого созыва. Предвыборные программы партий и избирательных блоков. [Электронный ресурс] // Официальный сайт Государственной Думы PФ URL: http://gd2003.cikrf.ru/partii.html

9. Предвыборная программа Президента // Аргументы и факты. 24 декабря 2003 г. № 52.

10. Спросите Зюганова [Электронный ресурс]. // Газета.ru. 2003. URL: https://www.gazeta.ru/zuganov.shtml 2003 (Дата 0бращения: 10.10. 2021)

11. Сергей Глазьев: «Долги в обмен на инвестиции - оптимальное решение для России» // Босc. 2003. № 1. URL: http://www.bossmag.ru/archiv/2003/boss-012003-g/sergey-glaz-ev-dolgi-v-obmen-na-investitsii-optimal-noe-reshenie-dlya-rossii.html (Дата обращения: 12.10. 2021)

12. Шаргородский А. Сергей Глазьев о предвыборной программе [Интервью]. 4 декабря 2003 г. Радио Свобода. Архив 1997 - 2004. URL: https://www. svoboda.org/a/24186976.html (Дата обращения: 12.10. 2021)

13. Римский В.Л. Президентская избирательная кампания 2004 года [Электронный ресурс] // Сайт Фонда ИНДEM. URL: https://indem.ru/idd2000/anal/ Rim436.htm (Дата обращения: 12.10.2021).

14. Мишкинене Ю. Кто предложит новый курс [Электронный ресурс] // Газета.ru. 29 апреля 2003 URL: https://www.gazeta.ru/comments/2003/04/22609.shtml (Дата обращения: 12.10.2021)

15. 0 нас [Электронный ресурс] // Сайт ООД «Развитие предпринимательства» URL: http://grachevid.ru/o-nas (Дата обращения: 15.10.2021)

16. Карпенко М., Казанцев В., Иванов А. Приоритетные национальные проекты и новая идеология. М: СГА, 2006. 126 с,

17. Послание Президента России В.В. Путина Федеральному собранию РФ от 16 мая 2003 г. [Электронный ресурс]. Президент России. Официальный сайт. URL: http://www.kremlin.ru/acts/bank/36352

18. Экономика переходного периода. Очерки экономической политики посткоммунистической России. Экономический рост 2000-2007. / Институт экономики переходного периода. Рук. авторского коллектива Е. Гайдар. М.: Дело. 2008.

19. РСПП и цивилизованный лоббизм: [сборник докладов и выступлений президента РСПП]. М.: Издательский дом РСПП, 2012. 289 с.

(c) Сукиасян Асатур Альбертович (saa@s-lab.info). 